\title{
A Formação nas Artes da Marionete no contexto da companhia Arketal em Cannes, França
}

La Formation aux Arts de Marionnette dans le cadre de la Compagnie Arketal à Cannes France

Greta Bruggeman ${ }^{1}$ 


\section{Resumo}

Este texto é um breve relato sobre o trabalho de formação e pesquisa nas artes da Marionete realizado em Arketal França.

Palavras-chave: Artes da Marionete; formação do marionetista; Companhia Arketal

\section{Résumé}

Ce texte est un bref rapport sur le travail de formation et de recherche dans les arts de la Marionnette réalisé à Arketal - France.

Mosts-clés: Marionnette Arts; formation de marionnettiste; Compagnie Arketal 


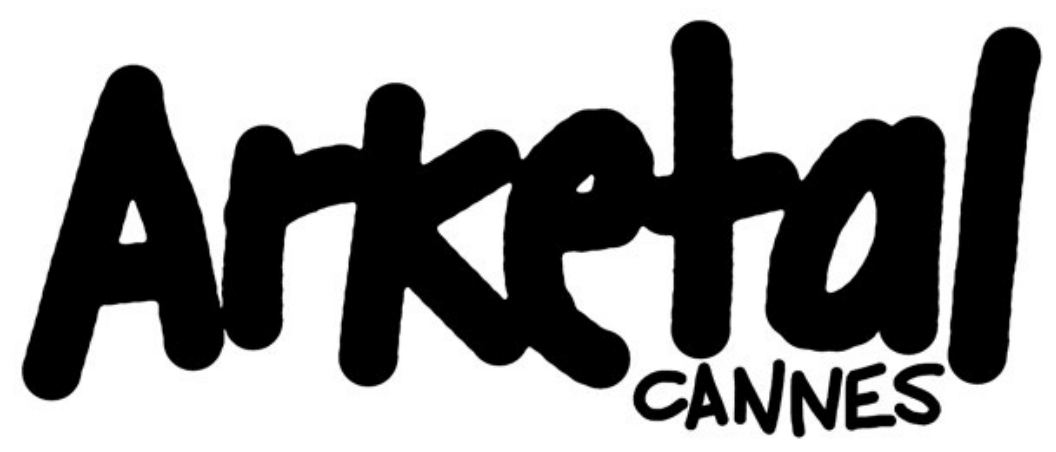

Escola de Marionetes ${ }^{2}$

\section{Objetivos e breve histórico}

O Ateliê de Arketal, centro de formação e de pesquisa nas artes da marionete, nasceu em 2002 de um desejo de transmissão e compartilhamento, bem como da necessidade de conceber um espaço de pesquisa e de criação.

Este centro de recursos, único no sudeste da França, destina-se aos profissionais do espetáculo e às pessoas envolvidas nos meios profissionais que precisam ser enriquecidos com essa prática. Promove a descoberta e a iniciação à expressão plástica e dramática contemporânea.

Para além da transmissão de técnicas, o ateliê de Arketal é um espaço de encontro aberto à aventura criativa, ao intercâmbio de saberes entre os participantes nos cursos e ao compartilhamento de experiências artísticas.

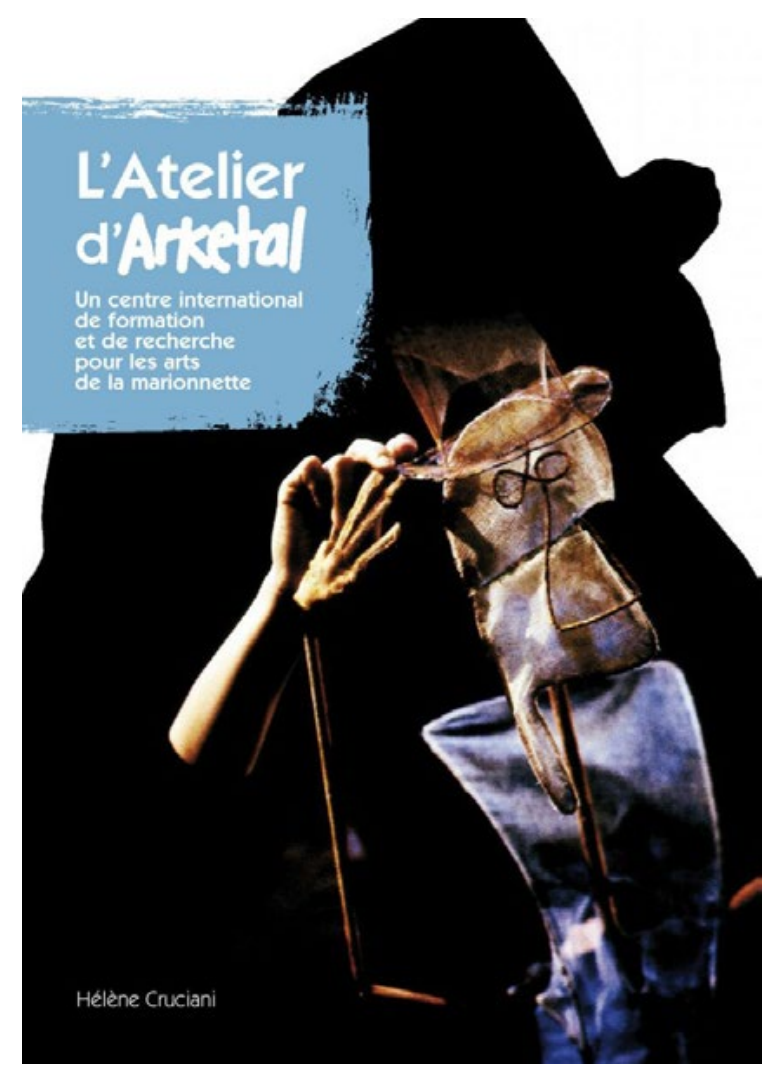

Fonte: http://arketal.com/autour-de-la-marionnette/

${ }^{2} \mathrm{http}: / /$ arketal.com 


\section{A formação inicial}

\section{A L'ERAC, École Régionale d'acteurs de Cannes (Na ERAC, Escola Regional de atores de Cannes)}

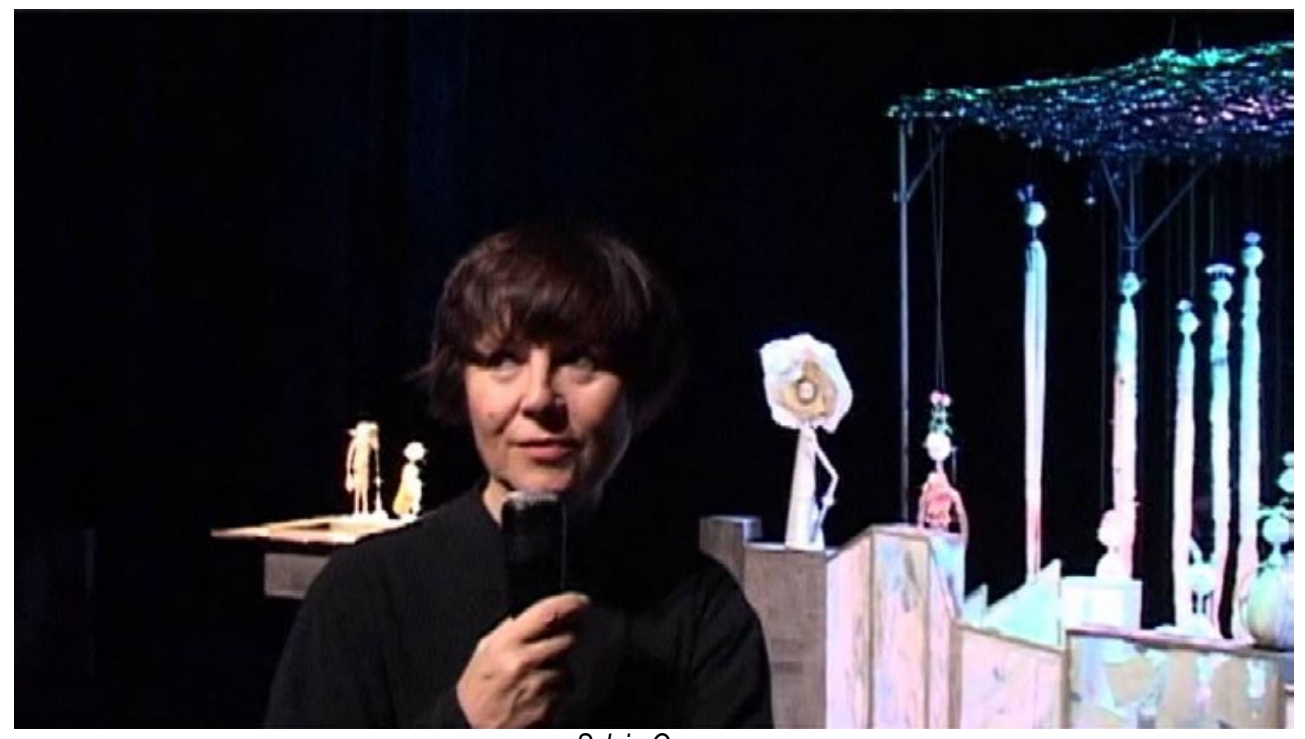

Sylvie Osman

Fonte: https://www.youtube.com/watch?v=Wu82XgE1h-Y. Marionetista e encenadora da compagnie Arketal.

Desde 2003, Sylvie Osman oferece uma oficina anual de iniciação ao teatro de marionetes com os alunos do $2^{\circ}$ ano.

O programa pedagógico é composto por três etapas:

1. Conscientização sobre o teatro de marionetes contemporâneo.

2. Abordagem da marionete enquanto instrumento: a técnica, as convenções, o movimento no espaço e os exercícios de base.

3. Estudo da arte dramática baseada em contos filosóficos, textos clássicos (Shakespeare, Sófocles...), textos de autores contemporâneos (Alfred Jarry, Patrick Kermann, Noël Renaude, Hanokh Levin, Carole Fréchette...).
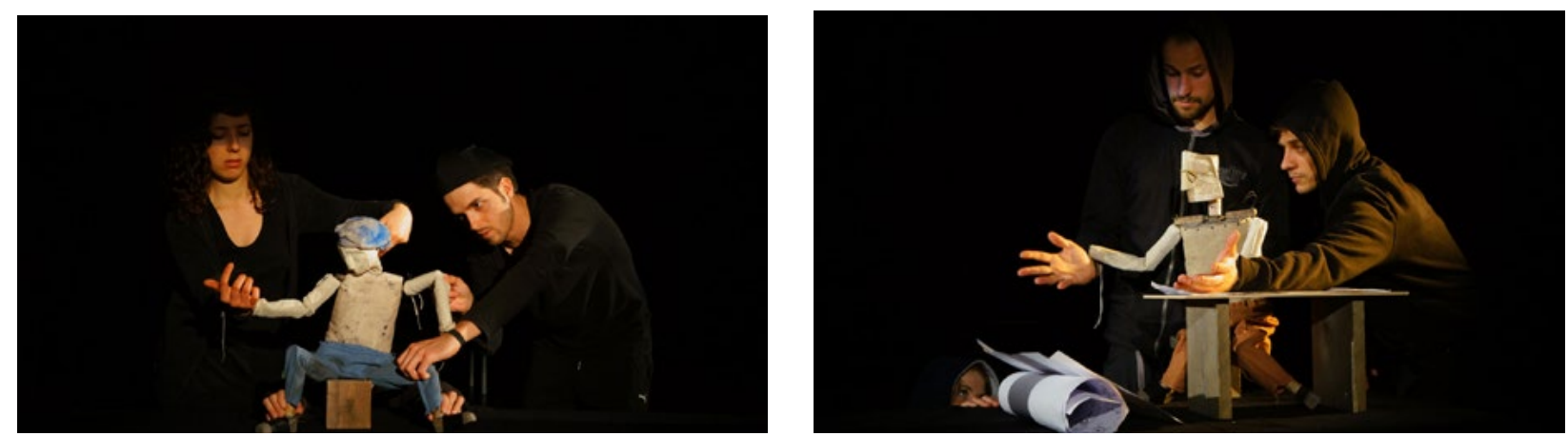

Inserção profissional: de 1992 a 2015: Orientação dos alunos-atores para os espetáculos da companhia.

Formação do ator marionetista - Arketal - Fase Inicial

Fonte: http://arketal.com/portfolio/formation-de-lacteur-marionnettiste/ 


\section{Na ESNAM}

\section{Escola Superior Nacional das Artes da Marionete de Charleville-Mézières}

Uma oficina de construção de uma marionete de vara, com Greta Bruggeman, a partir de figuras do pintor russo Malévich e interpretação de Sylvie Osman, baseada na poesia de Ossip Mandelstamm, com os alunos do 3ำ ano da 10ํㅡ turma.

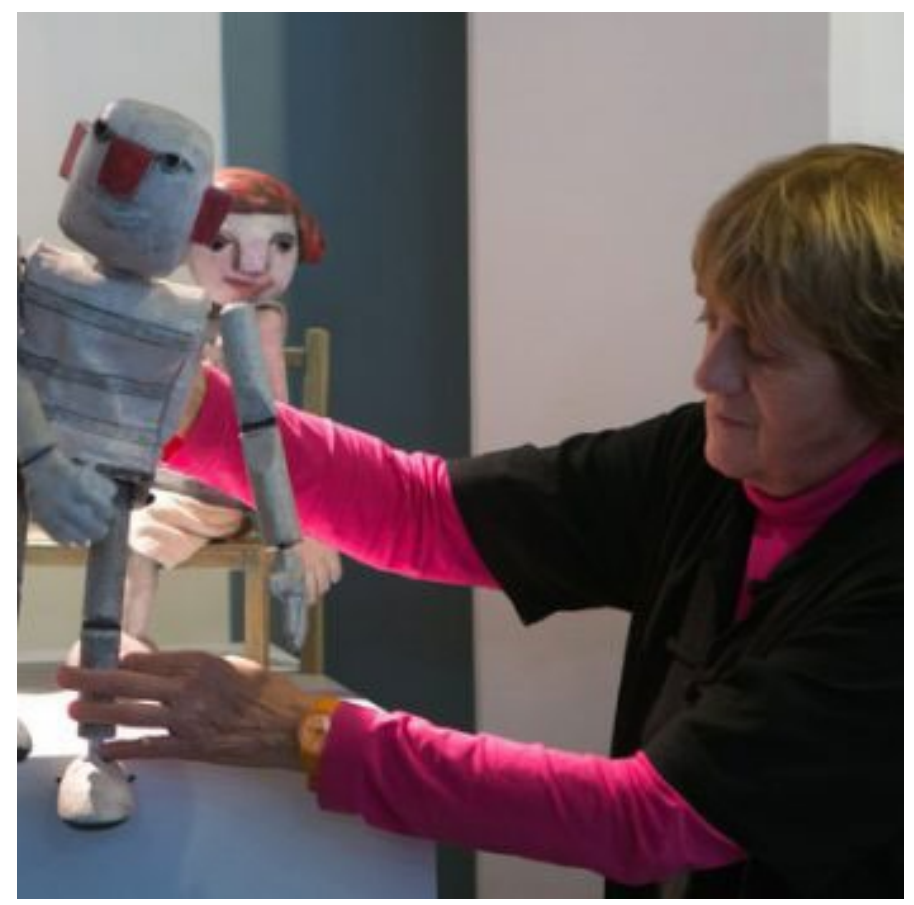

Greta Bruggeman ${ }^{3}$ - Designer e construtora de marionetes, cenógrafa da Companhia Arketal Fonte: http://arketal.com/portfolio/stages-professionnels-marionnette/

\section{No Théâtre aux Mains Nues de Paris - Escola do ator marionetista}

Formação continuada. Intervenção no contexto de formação em longo prazo: Construção de uma marionete de vara, de 5 a 15 de janeiro de 2015.

Laboratório Mise en Forme Mise en Jeu, a partir de poemas de Adonis e caligrafias do pintor Rachid Koraïchi, de 9 a 11 de janeiro de 2015.

\section{A formação continuada}

Arketal foi hospedada pela cidade de Cannes em uma antiga fábrica de calçados. O local dispõe de um ateliê equipado com ferramentas, instrumentos e os materiais necessários para a fabricação das marionetes e dos cenários.

\footnotetext{
${ }^{3}$ Ela também colabora com outras companhias para a construção de marionetes. Seus personagens são frequentemente projetados a partir de um desenho, uma pintura. As artes plásticas, desde o início, alimentam sua pesquisa. Fonte: http://arketal.com/portfolio/stages-professionnels-marionnette/
} 


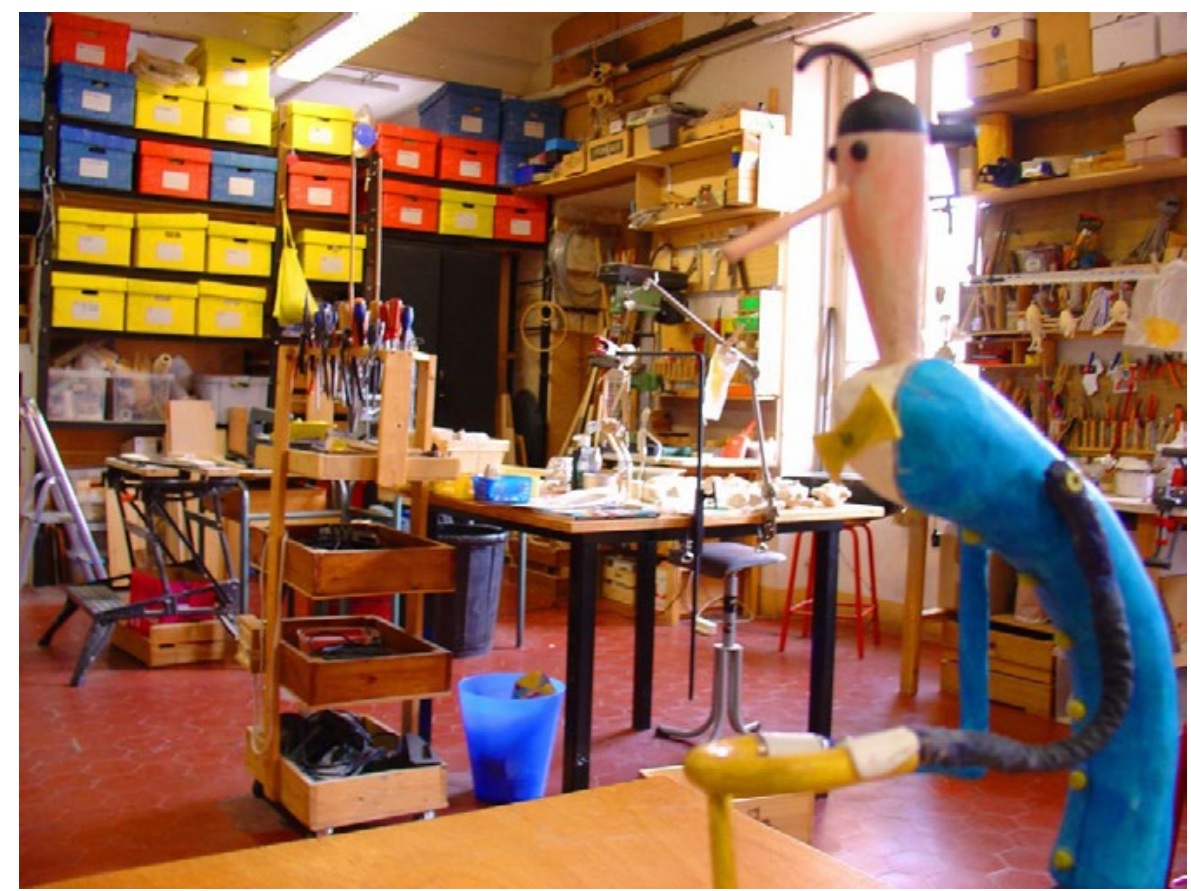

Ateliê de Arketal

Fonte: http://arketal.com/ecole-de-marionnettes-a-cannes/

Um pequeno estúdio de ensaio. Marionetes de pesquisa e protótipos ficam em exposição permanente. Uma biblioteca com obras sobre o Teatro de marionetes, o Teatro, as Artes Plásticas e Contos ficam à disposição dos estagiários.

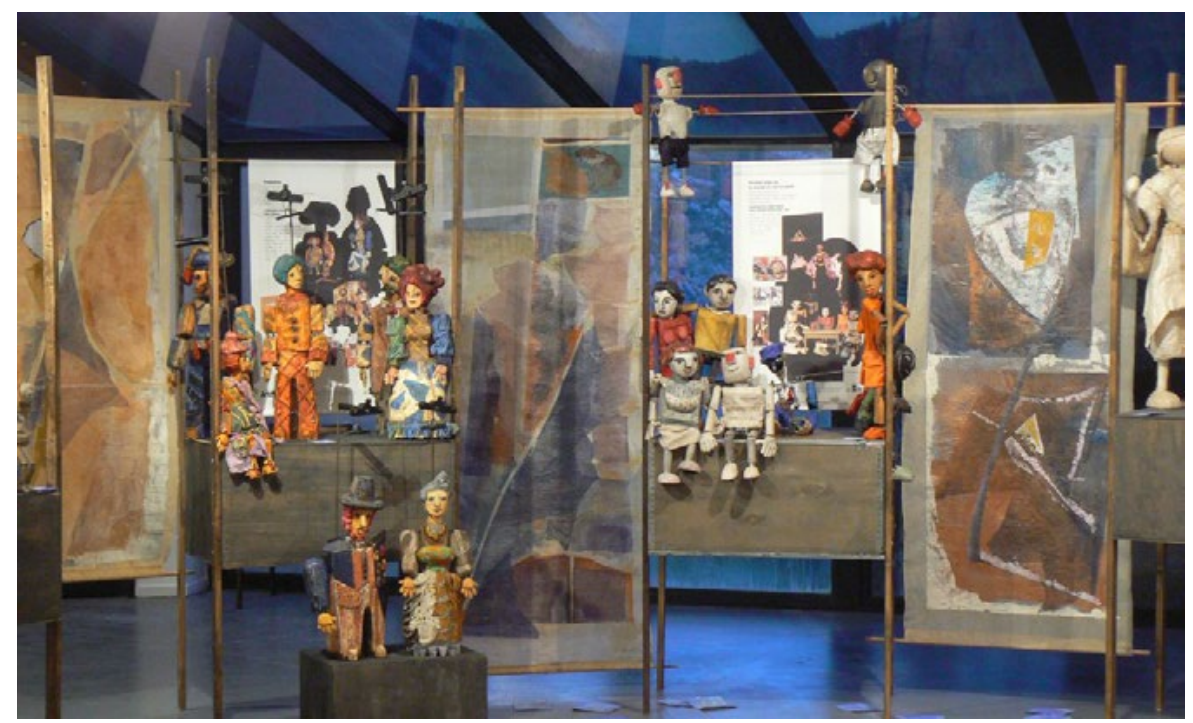

Exposição permanente dos protótipos de Arketal

Fonte: http://arketal.com/ecole-de-marionnettes-a-cannes/

Há mais de 15 anos e mais de sessenta oficinas, o Ateliê está em constante evolução. Além da construção de vários tipos de marionetes e encenações, foram adicionadas a exploração da escrita, da cenografia e da costura.

Muitos artistas, especialistas ou mestres em sua especialidade intervieram, palestrantes no campo das artes da marionete como: 
Frank Soehnle que pratica Marionete de Fio, a construção e a interpretação, um teatro muito contemporâneo baseado em técnicas clássicas.

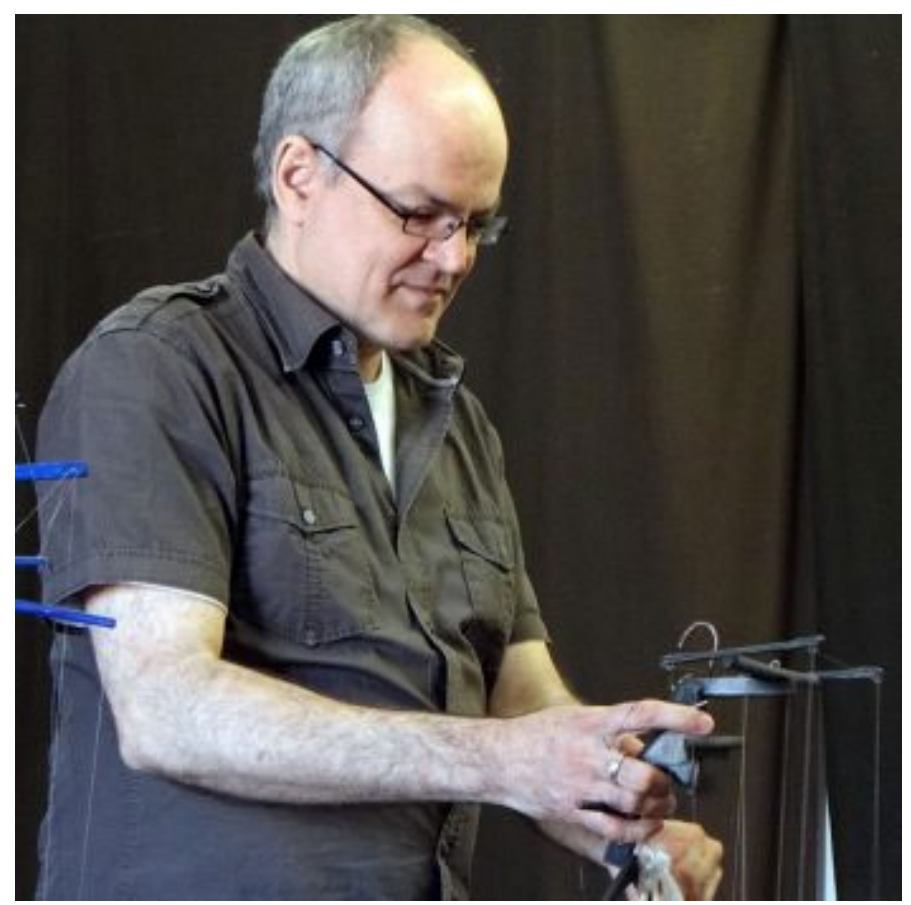

Frank Soehnle

Fonte: http://arketal.com/formation-marionnettiste/\#LEMERCIER

Thomas Lundqvist é um artista sueco que ensina a construção e a escultura de marionetes Bunraku, usando métodos e ferramentas japonesas. Pierre Blaise é ator e marionetista francês, aborda a interpretação, a marionete.

Emilie Flacher é uma jovem encenadora francesa, também construtora de marionetes. Ela se concentra na interpretação e na dramaturgia de textos contemporâneos.

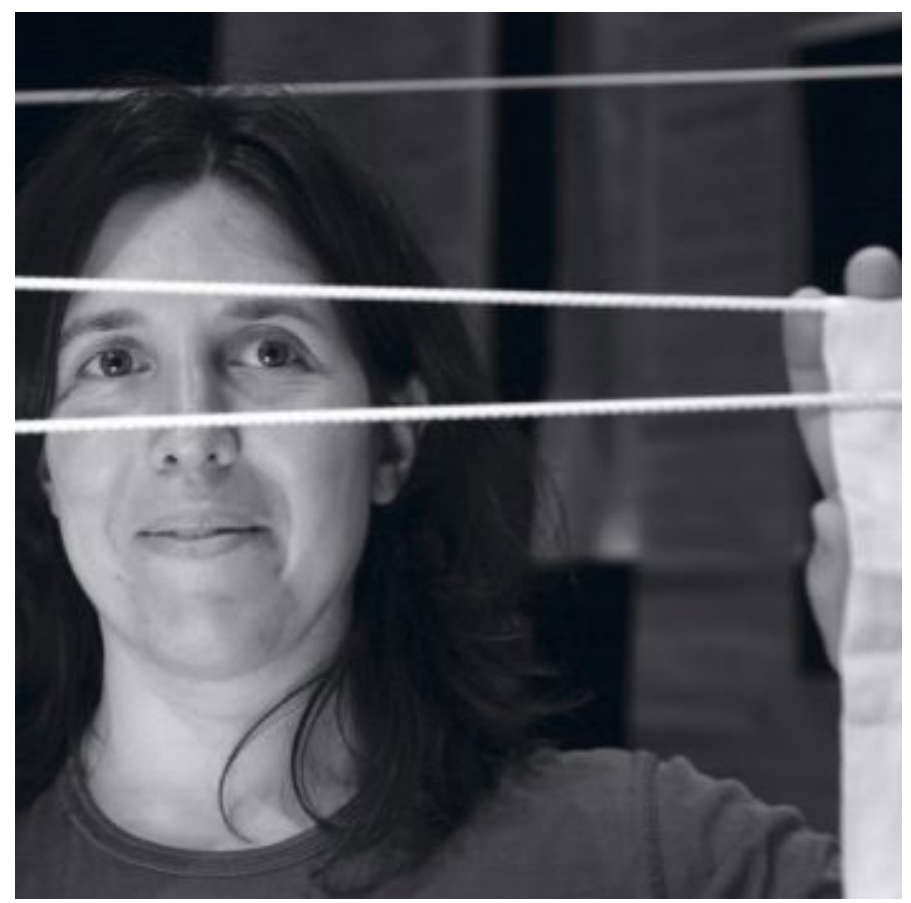

Emily Flacher

Fonte: http://arketal.com/portfolio/stages-professionnels-marionnette/ 
Alain Lecucq e Narguess Majd são especialistas em teatro de papel, da dramaturgia à encenação.

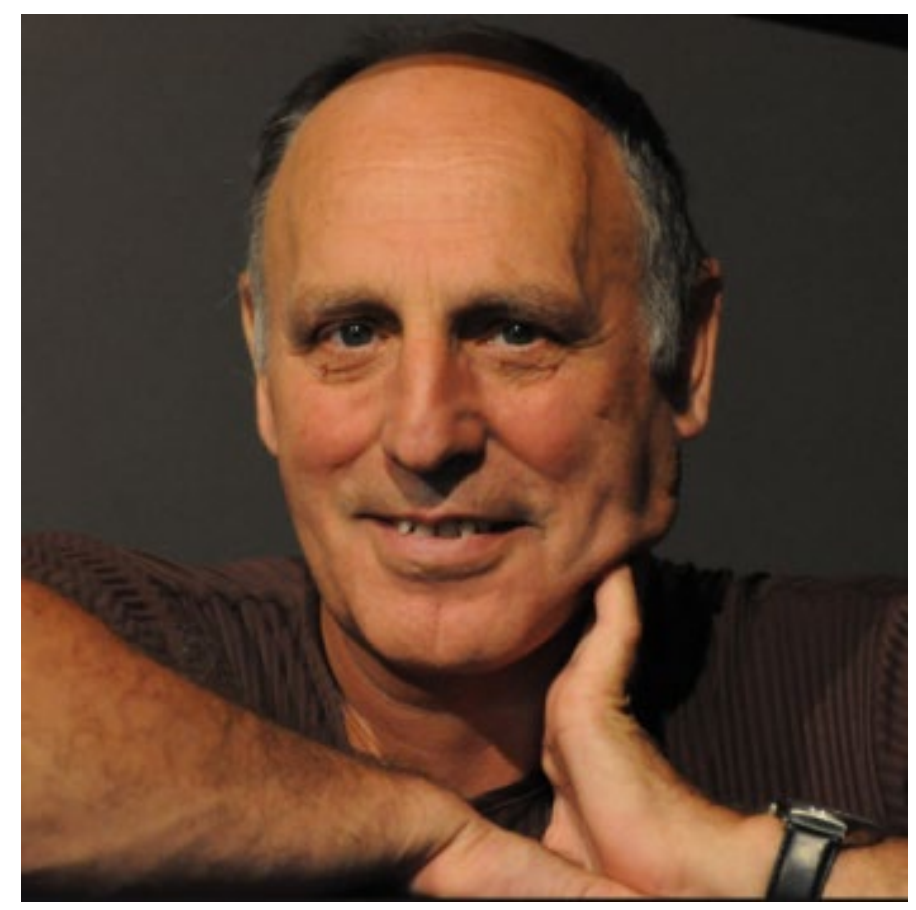

Jean-Pierre Lescot é um grande criador do teatro das sombras. Fonte: http://arketal.com/portfolio/stages-professionnels-marionnette/

Neste ano (2017) Joan Baixas vem pela primeira vez com o programa "Oh la la La marionnette".

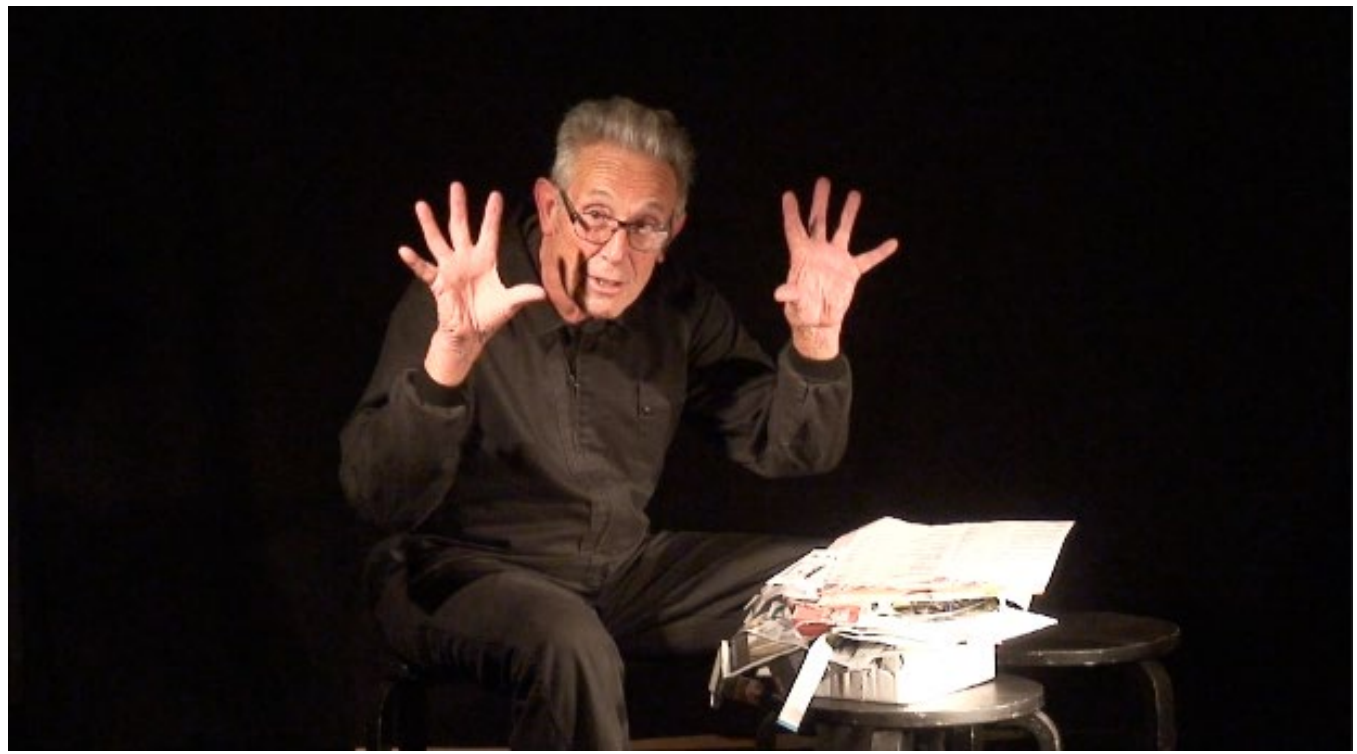

Joan Baixas - artista catalão

Fonte: http://arketal.com/rencontre-joan-baixas/

Tivemos o prazer de receber a artista cenógrafa Julia Skuratova, da Lituânia, o autor Jean Cagnard, os pintores Rolf Ball, Marius Rech e Michel Rauscher.

Nos últimos anos, temos convidado Damien Schoëvaërt-Brossault, que vem para ensinar o pop-up e o teatro de marionetes. 


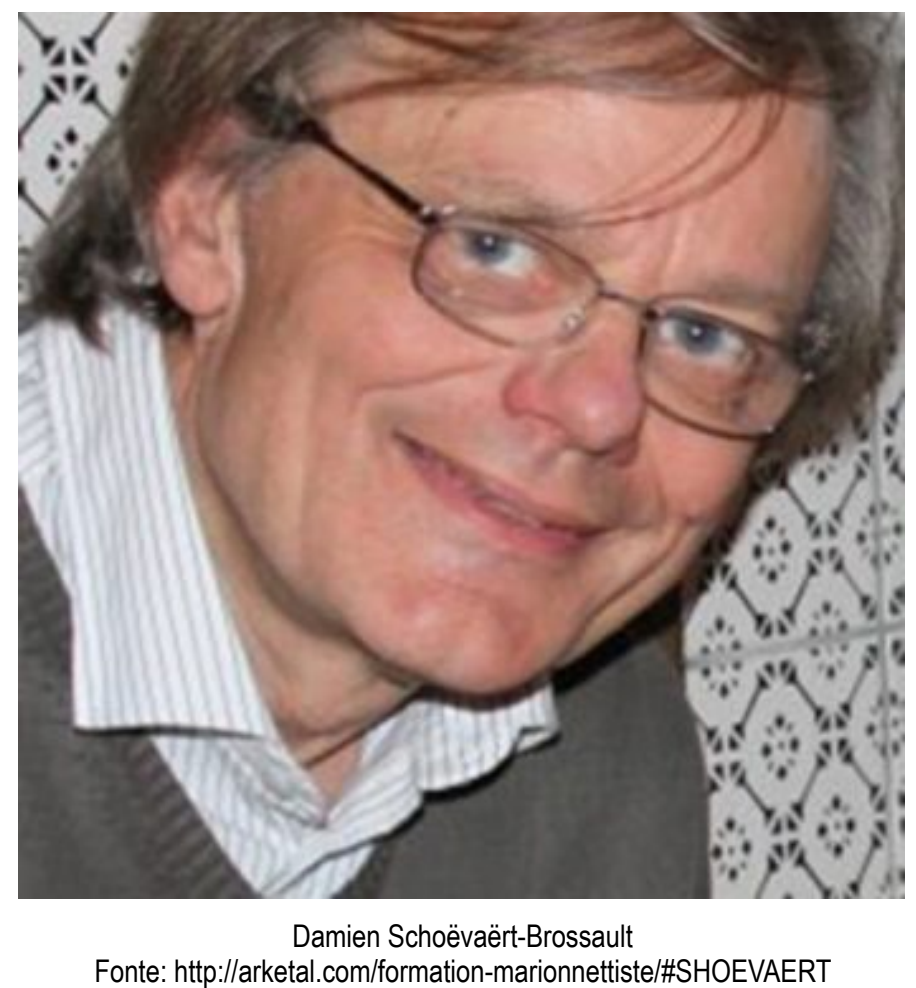

Sylvie Osman aborda a interpretação e eu a construção de marionetes, todo ano.

O programa anual "Mise en Forme Mise em Jeu" ocorre durante um período de 2 a 3 meses no início do ano. Este ciclo é composto de diferentes módulos complementares: tem início com o aprendizado das técnicas básicas para, então, passar às técnicas mais específicas. Essa formação completa e estruturada é acessível na forma de ciclo, mas também de forma modular para aqueles que assim desejarem.

O programa em sua totalidade pode ser uma preparação para a entrada no ESNAM (Escola em Charlleville) ou ser uma possibilidade de descoberta, de aprofundamento ou de mudança de rumo profissional.

Os estagiários, da França inteira ou de outros lugares, vêm e voltam ao Ateliê, Marionetistas, Atores, Cenógrafos, Encenadores, Artistas Plásticos, Contadores de histórias, Cantores, Estudantes. O Ateliê, através de seus objetivos, reúne pessoas de origens muito diversas. A duração de cada estágio - de uma a 3 semanas - dá tempo para os participantes imergirem totalmente no mundo da "Assurance Formation" marionete e, sobretudo, de agregar, a seu ritmo, novos caminhos de criação.

Confrontação de pontos de vista, intercâmbio de técnicas, partilha de conhecimentos, desenvolvimento de um espírito artístico e artesanal na utilização de materiais, pesquisa do movimento, invenção de formas novas...: durante os estágios, o Ateliê de Arketal entra em ebulição.

O Ateliê de Arketal abre as portas inúmeras reflexões sobre o objeto marionete. Durante os estágios, as mesas redondas entre estagiários e/ou artistas são momentos privilegiados que permitem a cada um de revelar suas próprias dificuldades, descobertas ou interrogações, impregnando-se das dos outros.

Os estágios terminam com um "puppet café" ("boneco café"), para apresentar a um público limitado o trabalho, e para conhecer o palestrante e os estagiários.

Este ciclo completo de formação é certificado pela AFDAS (Assurance Formation des Activités du Spectacle). 
Os estagiários franceses, os artistas do espetáculo, beneficiam-se de uma ajuda financeira para a formação. Quando eles trabalham, pagam uma cota, que é obrigatória. A cada ano eles têm o direito de se formar por uma instituição de formação reconhecido.

\section{A formação dos amadores}

As demandas por parte dos palestrantes artistas, educadores, professores, terapeutas, ou iniciantes são inúmeras. Esses estágios de iniciação ou de descoberta da construção e da interpretação são organizados fora do calendário escolar, durante o verão ou o outono. O público também vem de toda a França.

\section{As ações culturais}

As coordenações dos setores culturais das cidades ou dos teatros pedem ações culturais, ateliês nas escolas para abordar a criação de figuras simples e a aprendizagem da encenação.

Estas ações se desenvolvem a cada ano e se voltam às crianças do ensino primário, do fundamental e do médio.

\section{Ateliês Nômades}

Arketal oferece também formações no exterior, a pedido de festivais, e com frequência durante turnês no exterior. A participação no Festival Charleville-Mézières com exposições tornou conhecida a abordagem da concepção, da construção e da interpretação de marionetes.

Sylvie Osman e Greta Bruggeman fizeram intervenções nos últimos anos em Tolosa, em Sevilha e em Valência, na Espanha; no Instituto Francês em Porto Príncipe no Haiti; no Centre El Arca em Havana, em Cuba; no Centre Tournesol em Beirute, no Líbano, em Turku...

\section{As residências}

Há na França um mecanismo do Ministério da Cultura, "Le compagnonnage", que permite a um ou uma jovem artista ser acompanhado em um projeto pessoal e ao mesmo tempo de participar de um projeto da companhia. Ele se destina a jovens que saíram de uma école national (instituto federal). Nós acolhemos uma antiga aluna em sua saída do ESNAM. Erika residiu durante seis meses no Ateliê, descobrindo todas as facetas da vida da companhia (administração, gestão, difusão, comunicação). 0 acordo consiste em um verdadeiro contrato de profissionalização. A jovem marionetista participou, enquanto marionetista, do espetáculo de Arketal, L'homme qui plantait des arbres (O homem que plantava árvores), enquanto Arketal a apoiava na realização de seu projeto pessoal (maquete seguida da produção do espetáculo De fil en aiguille - De fio para agulha). 
Podem ocorrer outras residências, chamadas estágios "Air Libre" ("Ar Livre"), de uma ou algumas semanas nas quais um antigo aluno do Ateliê vem buscar acompanhamento para um projeto pessoal. Estes estágios ocorrem fora dos períodos de formação habituais e oferecem aos alunos uma imersão total, propícia à criação bem como ao aprofundamento dos conhecimentos.

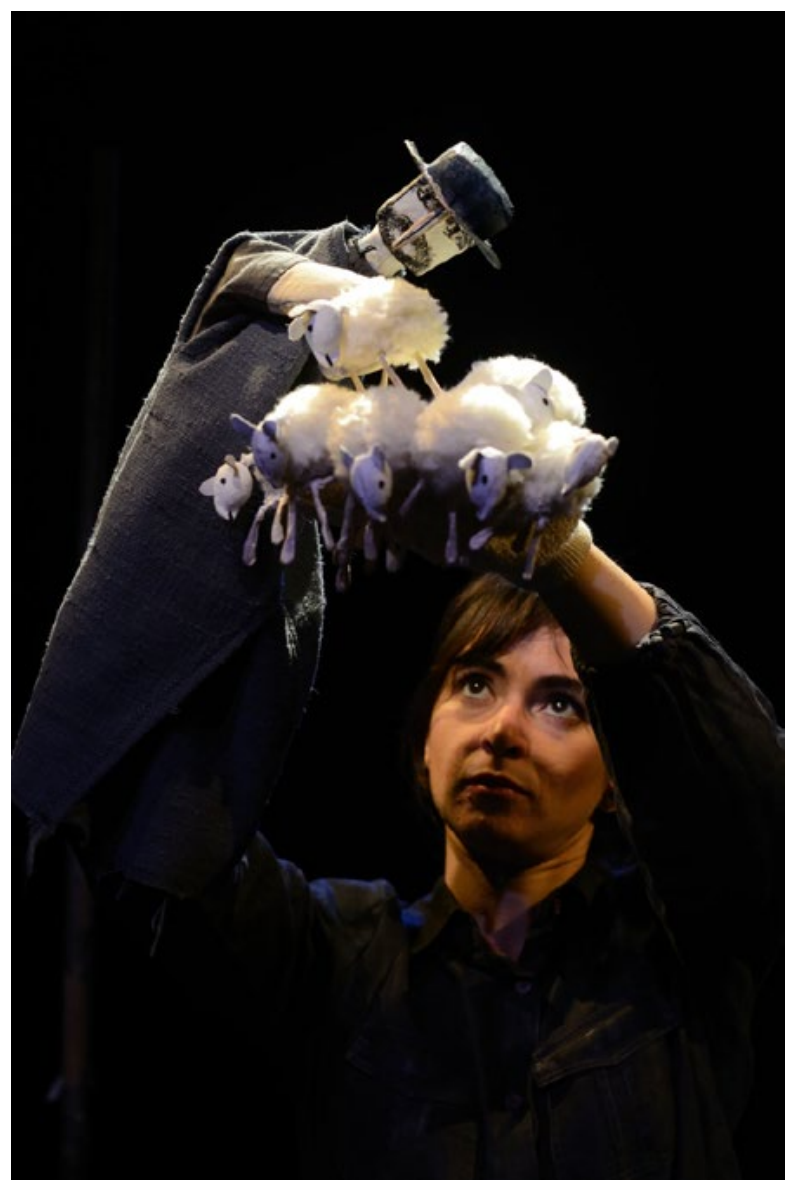

O homem que plantava árvores ${ }^{4}$

\section{O vínculo internacional e com a UNIMA}

O Ateliê buscou desde o início ser um lugar aberto. Todos nossos professores em Charleville vinham de outros países da Europa, assim como 2 terços dos alunos, que vinham do mundo inteiro. Na saída de Charleville, Michael Meschke e Henryk Jurkowsky nos convidaram e encorajaram a ir a seu país. Nós éramos 6 antigos alunos indo do Oeste para o Leste da Europa para apresentar na Suécia e na Polônia nossos primeiros "work in progress".

Nós mantivemos, até hoje, este espírito cultural transfronteiriço, em nossas abordagens criativas, em nossos encontros e descobertas artísticas e também na recepção de estagiários do mundo inteiro em nosso ateliê. Finlândia, Espanha, Dinamarca, Suíça, Bélgica, Holanda, Suécia, do Líbano, do Haiti, Estados Unidos, Itália e China.

\footnotetext{
${ }^{4}$ Espetáculo de novembro de 2013. Texto, Jean Giono/ Direção, Sylvie Osman / Marionetista, Erika Faria de Oliveira/ Ator Pierre Blain/ Conselho de dramaturgia, Christiane Samuel/ Escrita do texto do deputado, Jean-Baptiste Corbier/ Concepção cenográfica e design dos personagens Antoine Oriola/ Construção das marionetes e cenários, Greta Bruggeman/ Trilha sonora, Thomas Hocquet/ Criaçào da iluminação, Emmanuel Guedj. Espetáculos para todas as idades, a partir de 7 anos. Duração $50 \mathrm{~mm}$.
} 
Arketal é ajudado e sustentado pelo Ministério da Cultural, pela Région Provence Alpes Côte d'Azur, pelo Département des Alpes maritimes e por La Ville de Cannes.

Greta Bruggeman

Cannes, 3 de abril de 2017

Este texto traduzido, do francês, por Marina Bento Veshagem e Leide Daiane de Almeida Oliveira, e também se encontra publicado em francês neste número do periódico. Doutorandas pelo Programa de Pós-graduação em Estudos da Tradução, Universidade Federal de Santa Catarina (UFSC).

maveshagemagmail.com / daiane.deao@gmail.com

Recebido em: 29/05/2018

Aprovado em: 29/05/2018 